\title{
Photochemistry and Photophysics of Antimony(III) Hyper Porphyrins: Activation of Dioxygen Induced by a Reactive sp Excited State
}

\author{
Günther Knör* and Arnd Vogler* \\ Institut für Anorganische Chemie, Universität Regensburg, \\ Universitätsstrasse 31, D-93040 Regensburg, Germany
}

Received August 26, $1993^{\circ}$

\begin{abstract}
Observations of the photoredox reactivity of antimony(III) porphyrin complexes are reported. Upon irradiation with visible light under ambient conditions, a photooxidation to the corresponding dihydroxoantimony $(V)$ porphyrins occurs. At the same time a two-electron or four-electron reduction of molecular oxygen takes place, depending on the experimental conditions. In the absence of suitable electron acceptors, a photoinduced disproportionation reaction occurs. The photolysis of antimony(III) porphyrins shows a pronounced wavelength dependence. The reactive excited state is concluded to be of the metal-centered sp type. An extended model for the electronic structure of p-type hyper metalloporphyrins is suggested.
\end{abstract}

\section{Introduction}

Metalloporphyrins are essentially involved in various fundamental biological processes, such as electron transport, catalysis of redox reactions, storage and transport of oxygen, and photosynthetic energy conversion. ${ }^{1-6}$ This remarkable diversity of functions is achieved by suitable modifications of their basic electronic structure. Especially the electrons located on the central atom and its axial ligands play a crucial role in the control of the catalytic properties of metalloporphyrins. ${ }^{7}$ Redox reactivity involving the central atom generally requires that at least two stable oxidation states be available to the metal and that the energy of the metal valence orbitals match the region of the porphyrin $\pi$ levels. Well-documented examples of this case are the iron and manganese porphyrins. ${ }^{8,9}$ Theoretical studies predict these particular electronic properties also for the porphyrin complexes of lower valent group 14 and group 15 elements. ${ }^{10-13}$

Usually, due to a strong perturbation of the ligand $\pi$ system, the occurrence of irregular optical spectra ${ }^{14}$ indicates the presence of additional valence orbitals in the porphyrin frontier orbital region. The electrons of the central substituent are frequently involved in low-energy excited states of irregular metalloporphyrins. This feature makes them promising candidates for photocatalysts, particularly when a redox-active metal is coor-

- Abstract published in Advance ACS Abstracts, December 15, 1993

(1) Hemes and Hemoproteins; Chance, B., Estabrook, R. W., Yonetani, T., Eds.; Academic Press: New York, 1966.

(2) Lemberg, R.; Barrett, J. Cytochromes; Academic Press: New York 1973.

(3) The Porphyrins; Dolphin, D., Ed.; Academic Press: New York, 1978 Vol. VII.

(4) Cytochrome P-450: Structure, Mechanism and Biochemistry; Oritz de Montellano, P. R., Ed.; Plenum Press: New York, 1986.

(5) Chlorophylls, Scheer, H., Ed.; CRC Press: Boca Raton, FL, 1991

(6) (a) The Biological Role of Porphyrins and Related Structures; Adler A. D., Ed.; Annals of the New York Academy of Science, Vol. 244; New York Academy of Science: New York, 1975. (b) Harriman, A. In Energy Resources through Photochemistry and Catalysis; Grätzel, M. Ed.; Academic Press: New York, 1983; Chapter 6.

(7) Rawlings, D. C.; Davidson, E. R.; Gouterman, M. Int. J. Quantum Chem. 1984, 26, 251-274.

(8) Iron Porphyrins; Lever, A. B. P., Gray, H. B., Eds.; Addison-Wesley Reading, MA, 1983; Parts I and II

(9) Boucher, L. J. Coord. Chem. Rev. 1972, 7, 289-329.

(10) Schaffer, A, M.; Gouterman, M. Theor. Chim. Acta 1970, 18, 1-13.

(11) Hanson, L. K.; Eaton, W. A.; Sligar, S. G.; Gunsalus, I. C.; Gouterman M.; Connell, C. R. J. Am. Chem. Soc. 1976, 98, 2672-2674.

(12) Connell, C. R. Ph.D. Thesis, Department of Chemistry, University of Washington, Seattle, WA, 1977.

(13) Sayer, P.; Gouterman, M.; Connell, C. R. J. Am. Chem. Soc. 1977, 99 1082-1087.

(14) Gouterman, M. In The Porphyrins; Dolphin, D., Ed.; Academic Press New York, 1978; Vol. III, Chapter 1.

$0020-1669 / 94 / 1333-0314 \$ 04.50 / 0$ dinated. However, reports on light-induced redox reactions, changing the formal oxidation state of the central atom, are still rare in the field of metalloporphyrin photochemistry. ${ }^{15,16}$ The preponderance of observations is limited to chromium, manganese, and iron porphyrins, ${ }^{17}$ which display conspicuous irregular hyper absorption spectra. ${ }^{14,18}$ Metalloporphyrins containing low-valent main-group elements, such as $\mathrm{Sn}(\mathrm{II}), \mathrm{Pb}(\mathrm{II}), \mathrm{P}(\mathrm{III}), \mathrm{As}(\mathrm{III})$, $\mathrm{Sb}$ (III), and Bi(III), are also well-known for their irregular p-type hyper absorption spectra. ${ }^{14}$ Surprisingly the photochemistry of these compounds has never been investigated, although many of them are considered to be unstable and susceptible to spontaneous oxidation. From the viewpoint of potential applications in photocatalysis and solar energy conversion, light-sensitive coordination compounds of the main-group metals are of particular interest, since they are able to participate in photochemical multielectron-transfer reactions. ${ }^{19}$ Therefore we started to study the photophysical and photochemical properties of antimony porphyrins, with the intention of achieving a long-wavelength spectral sensitization of main-group-metal photoredox reactions.

The existence of low- and high-valent antimony porphyrins had first been mentioned ${ }^{20}$ more than 50 years ago. In earlier reports ${ }^{21,22}$ on the preparation of group 15 metalloporphyrins, however, the assignment of the formal oxidation states $\mathrm{Sb}$ (III) and $\mathrm{Sb}(\mathrm{V})$ had still been unsettled and has been reversed by later work. ${ }^{12,23}$ Relationships between the electronic structures of lower valent antimony porphyrins and the reduced heme groups of cytochrome P-450 and chloroperoxidase have been recognized by comparison of their absorption ${ }^{11}$ and magnetic circular dichroism ${ }^{24}$ spectra. The chemical and spectroscopic properties

(15) Hopf, F. R.; Whitten, D. G. In The Porphyrins; Dolphin, D., Ed.; Academic Press: New York, 1978; Vol. II, Chapter 6.

(16) Kalyanasundaram, K. Photochemistry of Polypyridine and Porphyrin Complexes; Academic Press: London, 1992.

(17) For a recent review see: Suslick, K. S.; Watson, R. A. New J. Chem. $1992,16,633-642$.

(18) (a) Buchler, J. W. In Porphyrins and Metalloporphyrins; Smith, K. M., Ed.; Elsevier: Amsterdam, 1975; Chapter 5. (b) Buchler, J. W. In The Porphyrins: Dolphin, D., Ed.; Academic Press: New York; 1978; Vol. I, Chapter 10.

(19) (a) Vogler, A.; Paukner, A.; Kunkely, H. Coord. Chem. Rev. 1990, 97, 285-297. (b) Vogler, A.; Nikol, H. Pure Appl. Chem. 1992, 64, 13111317.

(20) Treibs, A. Angew. Chem. 1936, 49, 31.

(21) Treibs, A. Justus Liebigs Ann. Chem. 1969, 728, 115-143.

(22) Buchler, J. W.; Lay, K. L. Inorg. Nucl. Chem. Lett. 1974, 10, 297-300.

(23) Stoppa, H. Doctoral Dissertation, Rheinisch-Westfălische Technische Hochschule Aachen, Germany, 1976.

(24) Dawson, J. H.; Trudell, J. R.; Barth, G.; Linder, R. E.; Bunnenberg, E.; Djerassi, C.; Gouterman, M.; Connell, C. R.; Sayer, P. J. Am. Chem. Soc. $1977,99,641-642$.

(C) 1994 American Chemical Society 
Table 1. Absorption Maxima ${ }^{a}$ and Band Splittings ${ }^{b}$ for $\left[(\mathrm{P}) \mathrm{Sb}^{\mathrm{III}}\right] \mathrm{Cl}$ Hyper Porphyrins in Ethanol at Room Temperature

\begin{tabular}{|c|c|c|c|c|c|c|c|c|c|c|}
\hline \multirow{2}{*}{$\begin{array}{l}\text { porphyrin } \\
\text { ligand }(\mathrm{P}) \\
\end{array}$} & \multicolumn{6}{|c|}{$\lambda_{\max } / \mathrm{nm}\left(10^{-3} \epsilon / \mathrm{L} \mathrm{mol} \mathrm{mom}^{-1}\right)$} & \multirow[b]{2}{*}{$\epsilon(\mathrm{II}) / \epsilon(\mathrm{I})$} & \multirow[b]{2}{*}{$\epsilon(\mathrm{II}) / \epsilon$ (III) } & \multicolumn{2}{|c|}{$\Delta E / \mathrm{cm}^{-1}$} \\
\hline & & I & I & & & I & & & $\overline{\text { I-II }}$ & $\overline{\text { II-III }}$ \\
\hline $\begin{array}{l}\mathrm{T}\left(p-\mathrm{OCH}_{3}\right) \mathrm{PP} \\
\text { TPP } \\
\text { OEP }\end{array}$ & $\begin{array}{l}345(34.5) \\
357(42.4) \\
355 \operatorname{sh}(30.1)\end{array}$ & $\begin{array}{l}385 \operatorname{sh}(24.8) \\
378 \operatorname{sh}(26.0) \\
376(64.0)\end{array}$ & $\begin{array}{l}445 \operatorname{sh}(29.1) \\
438 \operatorname{sh}(23.2) \\
430 \operatorname{sh}(21.1)\end{array}$ & $\begin{array}{l}469(166.2) \\
465(119.5) \\
460(46.4)\end{array}$ & $\begin{array}{l}600(6.0) \\
594(4.2) \\
570(9.0)\end{array}$ & $\begin{array}{l}655(11.9) \\
644(9.6) \\
600 \operatorname{sh}(2.9)\end{array}$ & $\begin{array}{r}13.97 \\
12.45 \\
5.16\end{array}$ & $\begin{array}{l}4.82 \\
2.82 \\
0.73\end{array}$ & $\begin{array}{l}6100 \\
6000 \\
4200\end{array}$ & $\begin{array}{l}7700 \\
6500 \\
4900\end{array}$ \\
\hline
\end{tabular}

${ }^{a} \mathrm{sh}=$ shoulder. ${ }^{b}$ Energy differences referring to the main band maxima.

of antimony porphyrins, together with those of other group 14 and group 15 metalloporphyrins, have been reviewed. ${ }^{25}$ Since then, no further accounts on antimony(III) porphyrins have appeared. The present study for the first time reports on observations of the photochemistry of antimony(III) porphyrins. Furthermore the nature of the reactive excited state is identified. On the basis of our results, we suggest an extension of the previous model ${ }^{14}$ for the electronic structure of p-type hyper metalloporphyrins.

\section{Experimental Section}

Materials. Pyridine (Fluka, puriss. p.a.) was distilled over molecular sieves under an argon atmosphere. Spectrograde solvents were used for the photophysical and photochemical investigations. Antimony trichloride (Aldrich, 99.99\%) was sublimated and stored under argon prior to use. The porphyrin ligands ${ }^{26}$ octaethylporphyrin (Fluka), tetrakis(p-methoxyphenyl)porphyrin (Aldrich), and tetraphenylporphyrin (Strem Chemicals) were purchased in the highest available qualities and used without further purification. The antimony(III) porphyrins were prepared according to established routes ${ }^{25}$ by the reaction of $\mathrm{SbCl}_{3}$ with the freebase porphyrin in dry pyridine under argon and reduced lighting. Ethano extraction of the crude material and filtration over silica gel were applied to remove traces of the free ligand. Dihydroxoantimony(V) porphyrins were readily obtained, as described previously for phosphorus porphyrins, ${ }^{27}$ by treatment of the corresponding antimony(III) compounds with $\mathrm{Br}_{2}$ and subsequent hydrolysis.

Spectroscopy. Absorption spectra were recorded with a Uvikon 860 double-beam spectrophotometer, and emission spectra were obtained on a Hitachi 850 spectrofluorimeter equipped with a Hamamatsu 928 photomultiplier. The luminescence spectra were corrected for monochromator and photomultiplier efficiency.

Photolyses. The light source was a Hanovia Xe/Hg 977 B-1 (1000 W) lamp. Monochromatic light was obtained by means of a Schoeffel GM 250-1 monochromator. All experiments were carried out at room temperature in stoppered $1-\mathrm{cm}$ quartz spectrophotometer cells. For quantum yield determinations, the complex concentrations were such as to have essentially complete light absorption and the total amount of photolysis was limited to less than $5 \%$ in order to avoid light absorption by the photoproducts. The absorbed light intensities were determined by a Polytec pyroelectric radiometer, which was calibrated and equipped with a RkP-345 detector. The progress of the photolysis was monitored by UV-visible spectrophotometry.

Analyses. For product analysis the photoreactions were driven to completeness. The metalloporphyrin photooxidation products were identified by comparison of their absorption spectra with those of the prepared antimony $(V)$ porphyrins. Additionally, the nature of their axial ligands was confirmed by field desorption mass spectrometry. Hydrogen peroxide was detected and quantitatively analyzed by the peroxidasecatalyzed oxidation of 4-aminophenazone in the presence of chromotropic acid. ${ }^{28}$

\section{Results}

As illustrated in Figure 1, the antimony(III) porphyrins display typical hyper absorption spectra ${ }^{14,18}$ with a red-shifted $\mathrm{Q}$ band (I) and a split Soret band (II, III). The spectral data for these

(25) Sayer, P.; Gouterman, M.; Connell, C. R. Acc. Chem. Res. 1982, 15, 73-79.

(26) Abbreviations used: meso-tetraphenylporphyrinato, TPP; meso-tetrakis(4-methoxyphenyl)porphyrinato, $\mathrm{T}\left(p-\mathrm{OCH}_{3}\right) \mathrm{PP}$; octaethylporphyrinato, OEP.

(27) Gouterman, M.; Sayer, P.; Shankland, E.; Smith, J. P. Inorg. Chem. $1981,20,87-92$

(28) Meiattini, F. In Methods of Enzymatic Analysis, 3rd ed.; Bergmeyer H. U., Ed.; VCH: Weinheim, Germany, 1985; Vol. VII, pp 566-571.

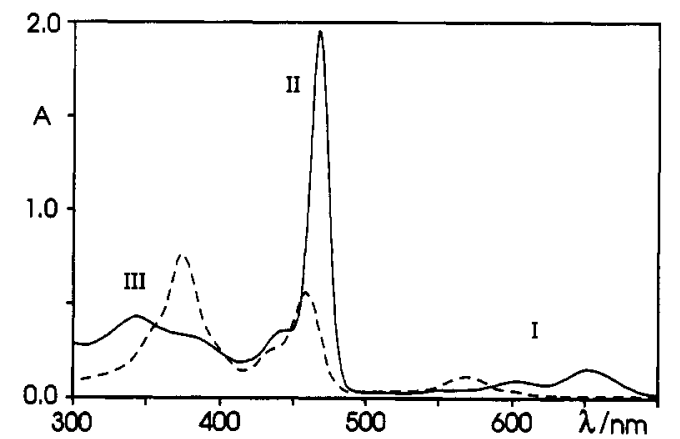

Figure 1. Electronic absorption spectra of $1.2 \times 10^{-5} \mathrm{M}\left[\left(\mathrm{T}\left(p-\mathrm{OCH}_{3}\right)-\right.\right.$ $\mathrm{PP}) \mathrm{Sb}] \mathrm{Cl}(-)$ and $[(\mathrm{OEP}) \mathrm{Sb}] \mathrm{Cl}(-\cdot)$ in ethanol (1-cm cell).

bands and their vibronic satellites are summarized in Table 1. As can be seen, the variation of the porphyrin ligand $P$ leads to significant changes of the $[(\mathrm{P}) \mathrm{Sb}] \mathrm{Cl}$ optical absorption spectra. Thus, in the series $\mathrm{T}\left(p-\mathrm{OCH}_{3}\right) \mathrm{PP}, \mathrm{TPP}$, and OEP, ${ }^{26}$ the ratios of the molar absorptivities $\epsilon$ (II) $/ \epsilon$ (I) and $\epsilon$ (II) $/ \epsilon$ (III) continuously decrease. At the same time, a decreasing energetic splitting between all bands occurs. Band III is more and more red-shifted, and further, its oscillator strength considerably increases. The observed spectral changes can be summarized as an increasing hyper character within the above series. Similar changes of the optical absorption spectra of main-group-metal hyper porphyrins upon variation of the central metal ${ }^{29}$ or its axial ligands ${ }^{30}$ have also been described.

The emission properties of the $[(\mathrm{P}) \mathrm{Sb}] \mathrm{Cl}$ complexes were investigated in degassed solutions at room temperature and in rigid glasses or snows at $77 \mathrm{~K}$. No authentic luminescence was observed for any of the antimony(III) porphyrins at room temperature. For the tetraarylporphyrin derivatives also, no lowtemperature luminescence could be detected. In ethanol or $\mathrm{CH}_{2-}$ $\mathrm{Cl}_{2}$ solution at $77 \mathrm{~K}$, the antimony(III) octaethylporphyrin complex displays a rather sharp, structureless emission band at $\lambda_{\max }=745 \mathrm{~nm}$ (Figure 3), shifted about $3200 \mathrm{~cm}^{-1}$ from the long-wavelength shoulder of band $I$. The excitation spectrum agrees well with the absorption spectrum of the metalloporphyrin at room temperature. A weak, short-lived phosphorescence at $740 \mathrm{~nm}$ had been reported previously 12,25 for [(OEP)Sb] $\mathrm{Cl}$ at 77 $K$ in EPA solution. ${ }^{31}$ The phosphorescence quantum yield had been measured as $\Phi_{P}=0.003$ and a lifetime of $88 \mu \mathrm{s}$ had been determined. According to the emission properties, [(OEP)Sb]$\mathrm{Cl}$ can therefore be classified ${ }^{14}$ as photophorescent, while the investigated antimony(III) tetraarylporphyrin derivatives apparently belong to the class of radiationless metalloporphyrins.

Unlike the closely related tin(II) porphyrins, which easily decompose in the presence of oxygen or traces of moisture, ${ }^{32}$ the antimony(III) complexes turned out to be remarkably stable under these conditions, as long as they were handled in the dark. Thus, $[(\mathrm{P}) \mathrm{Sb}] \mathrm{Cl}$ solutions in air-saturated ethanol or acetonitrile can be stored for many hours without the occurrence of spectral changes indicating decomposition or oxidation. Traces of acids, however, lead to a partial demetalation of the complexes. Upon

(29) Reference 14, p 107

(30) Guilard, R.; Lecomte, C.; Kadish, K. M. Struct. Bonding 1987, 64, 205-268; see p 212.

(31) EPA: diethyl ether-isopentane-ethanol $(5: 5: 2 \mathrm{v} / \mathrm{v})$

(32) Barbe, J.-M.; Ratti, C.; Richard, P.; Lecomte, C.; Gerardin, R.; Guilard, R. Inorg. Chem. 1990, 29, 4126-4130 and references therein. 


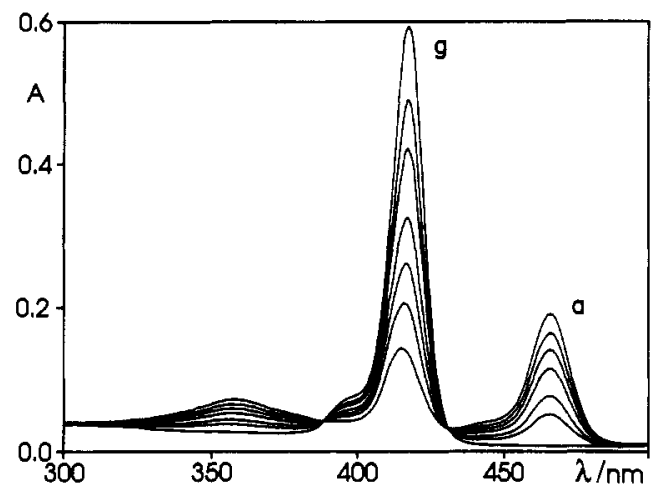

Figure 2. Spectral changes during the photolysis of $5.0 \times 10^{-6} \mathrm{M}$ [(TPP)$\mathrm{Sb} \mathrm{Cl}$ in ethanol in the presence of oxygen at (a) $0,2,4,6,8,10$, and (g) 12 min irradiation times with $\lambda_{\text {irr }}=436 \mathrm{~nm}(1-\mathrm{cm}$ cell).

exposure to visible light, the reactivity of the antimony(III) porphyrins increases drastically. When any of the investigated $[(\mathrm{P}) \mathrm{Sb}] \mathrm{Cl}$ compounds is irradiated in ethanol, acetone, or acetonitrile solution saturated with oxygen or air, the same type of photoreaction takes place. This photolysis is accompanied by spectral changes, which clearly indicate a conversion of the antimony(III) hyper porphyrins to their corresponding antimony(V) complexes, displaying normal type ${ }^{14}$ metalloporphyrin spectra with a regular Soret band in the $400-\mathrm{nm}$ spectral region (Figure 2). At the same time, hydrogen peroxide is formed as a permanent photoproduct. As indicated by the occurrence of several isosbestic points, ${ }^{33}$ the photooxidation of the antimony(III) porphyrins in the presence of oxygen is a very clean reaction, which can be driven to completeness.

The photochemistry of the [(OEP)Sb]Cl complex was studied in more detail. By means of field desorption mass spectrometry the metalloporphyrin photooxidation product was confirmed to be the dihydroxoantimony $(\mathrm{V})$ complex with a molecular ion peak for ${ }^{121} \mathrm{Sb}$ at $m / z=687$ corresponding to the [(OEP)Sb(OH) $)_{2}{ }^{+}$ cation. Only in $\mathrm{CH}_{2} \mathrm{Cl}_{2}$ solution, which can serve as a source for $\mathrm{HCl}$, was the monochloro cation [(OEP)Sb(OH) $(\mathrm{Cl})]^{+}$with $\mathrm{m} / z$ $=705$ identified as a second oxidation product. The total amount of hydrogen peroxide produced was rather high. In a typical experiment, a $1.3 \times 10^{-3} \mathrm{M}$ oxygen-saturated ethanolic solution of (octaethylporphyrinato)antimony(III) chloride, completely photolyzed at $\lambda_{\mathrm{irr}}=550 \mathrm{~nm}$, yielded $57 \% \mathrm{H}_{2} \mathrm{O}_{2}$ with regard to the overall stoichiometric equation

$$
\begin{aligned}
{\left[(\mathrm{OEP}) \mathrm{Sb}^{\mathrm{III}}\right] \mathrm{Cl}+\mathrm{O}_{2}+2 \mathrm{H}_{2} \mathrm{O} \stackrel{h \nu}{\rightarrow} } & {\left[(\mathrm{OEP}) \mathrm{Sb}^{\mathrm{V}}(\mathrm{OH})_{2}\right] \mathrm{Cl}+\mathrm{H}_{2} \mathrm{O}_{2} }
\end{aligned}
$$

In the beginning of the photolysis and for very dilute solutions, the recovery of hydrogen peroxide seemed to be almost quantitative. However, the detection limit of the $\mathrm{H}_{2} \mathrm{O}_{2}$ assay ${ }^{28}$ was reached under these conditions. The quantum yield for the formation of $\left[(\mathrm{OEP}) \mathrm{Sb}(\mathrm{OH})_{2}\right] \mathrm{Cl}$ was followed by the increase of optical density at $530 \mathrm{~nm}$, where the largest difference between the $Q$ band maxima of the reduced and oxidized forms of the metalloporphyrin exists $\left(\Delta \epsilon=8500 \mathrm{~L} \mathrm{~mol}^{-1} \mathrm{~cm}^{-1}\right)$. Interestingly, the quantum yield for the antimony(III) porphyrin photooxidation is not independent of the irradiation wavelength. Thus, for [(OEP)Sb] $\mathrm{Cl}$ in ethanolic solution, a maximum with $\Phi=1 \times$ $10^{-2}$ occurs at about $265 \mathrm{~nm}$, while, for $\lambda_{\text {irr }}>280 \mathrm{~nm}$, a constant value of $\Phi=3 \times 10^{-4}$ is reached. In $\mathrm{CH}_{2} \mathrm{Cl}_{2}$ solution, this quantum yield profile is red-shifted and two clearly resolved maxima can be observed at $290 \mathrm{~nm}$ and at about $400 \mathrm{~nm}$ with $\Phi=5 \times 10^{-2}$ and $\Phi=6 \times 10^{-3}$, respectively (Figure 3 ), while, toward longer

(33) Isosbestic points in ethanolic solution for the $\mathrm{Sb}$ (III) complexes of (a) $\mathrm{T}\left(p-\mathrm{OCH}_{3}\right) \mathrm{PP}$, (b) TPP, and (c) OEP: (a) 303, 314, 388, 451, 499 and $623 \mathrm{~nm}$; (b) $307,388,431,500,518,534,566,580$ and $596 \mathrm{~nm}$; (c) 325 , $384,409,516,544,566$ and $572 \mathrm{~nm}$.

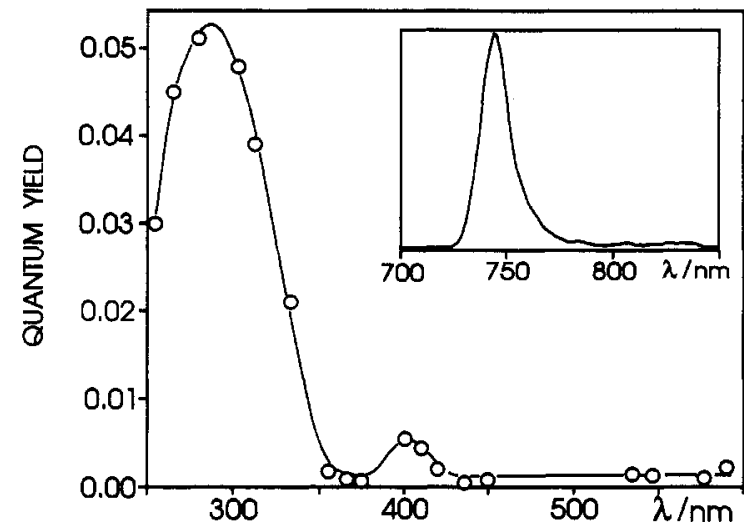

Figure 3. Quantum yield dependence on excitation wavelength for the photooxidation of $3.3 \times 10^{-4} \mathrm{M}[(\mathrm{OEP}) \mathrm{Sb}] \mathrm{Cl}$ in oxygen-saturated $\mathrm{CH}_{2-}$ $\mathrm{Cl}_{2}$ at room temperature. Inset: Corrected emission spectrum of [(OEP)Sb] $\mathrm{Cl}$ in $\mathrm{CH}_{2} \mathrm{Cl}_{2}$ at $77 \mathrm{~K}\left(\lambda_{\text {exc }}=577 \mathrm{~nm}\right.$; intensity in arbitrary units).

wavelengths, the quantum yield drops and a plateau with $\Phi=1$ $\times 10^{-3}$ occurs. For any selected irradiation wavelength, the quantum yield values were found to decrease within the solvent series $\mathrm{CH}_{2} \mathrm{Cl}_{2}$, acetone, ethanol, and acetonitrile.

Once exposed to visible light, the solutions of antimony(III) porphyrins could no longer be stored without being gradually oxidized. A very slow dark reaction with the photoproduct $\mathrm{H}_{2} \mathrm{O}_{2}$ was found to be responsible for this spontaneous process:

$$
\left[(\mathrm{P}) \mathrm{Sb}^{\mathrm{III}}\right] \mathrm{Cl}+\mathrm{H}_{2} \mathrm{O}_{2} \rightarrow\left[(\mathrm{P}) \mathrm{Sb}^{\mathrm{V}}(\mathrm{OH})_{2}\right] \mathrm{Cl}
$$

Under pseudo-first-order conditions with $8.6 \times 10^{-3} \mathrm{M}$ hydrogen peroxide and $8.5 \times 10^{-6} \mathrm{M}$ metalloporphyrin, the second-order rate constant for the reaction of [(OEP)Sb] $\mathrm{Cl}$ with $\mathrm{H}_{2} \mathrm{O}_{2}$ was determined as $k=2.7 \times 10^{-3} \mathrm{~L} \mathrm{~mol}^{-1} \mathrm{~s}^{-1}$ in ethanolic solution at room temperature. Probably this secondary reaction is strongly enhanced upon irradiation, so that at higher concentrations the photooxidation of antimony(III) porphyrins always yields less than stoichiometric amounts of hydrogen peroxide. Unfortunately, as identical antimony (V) complexes are formed in both possible oxidation pathways, the extent of such a secondary photolysis cannot be followed by the occurrence of additional spectral changes.

In the absence of electron acceptors, the irradiation of antimony(III) porphyrins in argon-saturated solution leads to a photoinduced disproportionation reaction. ${ }^{34}$ Free-base porphyrin, metallic antimony, and antimony $(V)$ porphyrin were identified as the final products in ethanolic solution. The spectral variations which accompany this photolysis, as well as the approximate quantum yields for the antimony (V) formation, are quite similar to those observed in the presence of oxygen. Due to the precipitation of free-base porphyrin and the formation of colloidal metal, however, the isosbestic points are lost after a short irradiation period. No further attempts were made to investigate this photoreaction in detail.

\section{Discussion}

In order to understand the properties of antimony(III) porphyrins, it is useful first to discuss the influence of the coordinating ligand on the central metal valence orbitals. For simplicity, ${ }^{35}$ the porphyrin macrocycle can be regarded as a rigid, planar $\sigma$-donor ligand with its four nitrogen atoms defining the $x y$ plane. Qualitative molecular orbital considerations show that

(34) No hydrogen formation was detected from [(OEP)Sb]Cl solutions by means of gas chromatography, so that $\mathrm{H}_{2} \mathrm{O}$ can certainly be ruled out as a possible electron acceptor under these photolysis conditions

(35) The porphyrin macrocycle displays a considerable conformational flexibility: Barkigia, K. M.; Renner, M. W.; Furenlid, L. R.; Medforth, C. J.; Smith, K. M.; Fajer, J. J. Am. Chem. Soc. 1993, I15, 3627-3635 and references therein. 


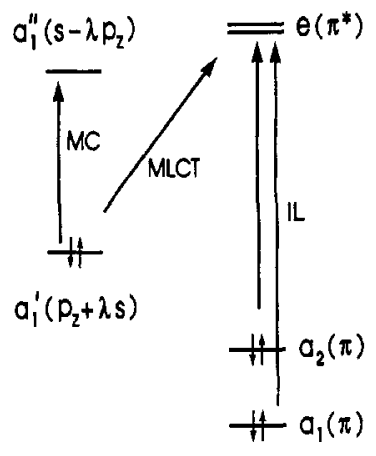

Metal

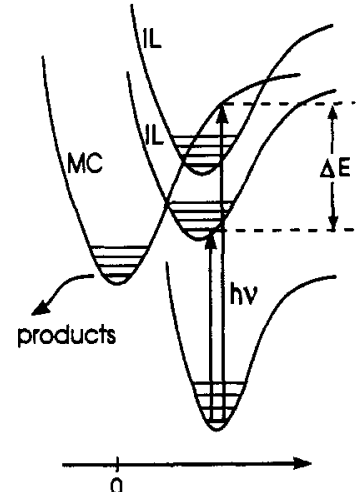

Metal out-of-plane displacement
Figure 4. Schematic representation of molecular orbitals (left side) and potential energy surfaces (right side) for p-type hyper metalloporphyrins, assuming square pyramidal geometry ( $C_{4 v}$ symmetry) for the groundstate complexes.

for a hypothetical square planar geometry $\left(D_{4 h}\right.$ symmetry) the antimony $5 \mathrm{p}_{z}$ orbital remains unaffected as a nonbonding HOMO, occupied by two electrons, while empty antibonding $\sigma$ MOs result from the metal $5 s$ and $5 p_{x, y}$ orbitals. It can be deduced that the molecule achieves a minimization of its total energy by a secondorder Jahn-Teller distortion ${ }^{36}$ from a planar to a square pyramidal structure $\left(C_{4 v}\right.$ symmetry). In this out-of-plane geometry, the MOs resulting from the antimony $5 s$ and $5 p_{z}$ orbitals are transformed to the same symmetry $\left(a_{1}\right)$ and a $\mathrm{sp}_{z}$ mixing can occur, which stabilizes the metal-centered HOMO. The degree of the out-of-plane displacement and of the $\mathrm{sp}_{z}$ hybridization is mainly ${ }^{37}$ limited by the $\sigma$-donor strength of the porphyrin ligand. Thus, the $s$ character of the antimony(III) lone pair, the complex geometry, and the energetic sp separation are determined by $\sigma$ interactions. The optical spectra and redox properties of the metalloporphyrin, however, are controlled by interactions between the modified metal valence orbitals and the $\pi$-electron system of the macrocyclic ligand.

A simplified qualitative one-electron MO diagram for p-type hyper porphyrins, which can be generalized for all low-valent group 14 and group 15 metalloporphyrins, is given in Figure 4. The metal-centered $\mathrm{e}\left(\mathrm{p}_{x, y}\right)$ orbitals, which are situated at higher energies and which lead to a stabilization of the porphyrin $\mathrm{e}\left(\pi^{*}\right)$ LUMOs, are omitted for clarity. As will be seen, the electronic spectra and the reactive excited states of p-type hyper metalloporphyrins can be derived from this six-orbital pattern. ${ }^{7}$ The lowest energy excitations involving electrons localized mainly on the porphyrin ligand correspond to the four-orbital transitions $a_{1}(\pi), a_{2}(\pi) \rightarrow e\left(\pi^{*}\right)$. The metal-centered HOMO has the same symmetry as and an energy comparable to those of one of the ligand top filled $\pi$ orbitals. Therefore the metal to ligand charge transfer (MLCT) transition $a_{1}{ }^{\prime}\left(p_{2}+\lambda_{s}\right) \rightarrow e\left(\pi^{*}\right)$ can mix by configuration interaction with the porphyrin intraligand (IL) transitions, ${ }^{14}$ inducing the diagnostic hyper absorption spectrum. Further, the metal-centered (MC) electronic transition $\mathrm{a}_{1}{ }^{\prime}\left(\mathrm{p}_{z}+\right.$ $\left.\lambda_{s}\right) \rightarrow a_{1}{ }^{\prime \prime}\left(s-\lambda p_{z}\right)$ occurs at rather low energies. Symmetry considerations show that this allowed transition is unable to mix with the $\pi \pi^{*}$ transitions of the porphyrin ligand. Therefore it can be regarded as a pure sp electronic transition, ${ }^{38}$ involving mainly the valence electrons of the central metal.

In terms of this model, the spectroscopic properties of the antimony(III) porphyrins can be interpreted. For the tetraarylporphyrin derivatives, which display only a moderate hyper

(36) Albright, T. A.; Burdett, J. K.; Whangbo, M.-H. Orbital Interactions in Chemistry; Wiley: New York, 1985.

(37) Axial perturbations by the counterion or by solvent molecules may become dominant for porphyrin ligands with a low electron-donor capacity.

(38) Vogler, A.; Nikol, H. Comments Inorg. Chem. 1993, 14, 245-261 and references therein. character, absorption bands I and II can be regarded as redshifted intraligand $Q$ and Soret bands, derived from the porphyrin four-orbital transitions $a_{1}(\pi), a_{2}(\pi) \rightarrow e\left(\pi^{*}\right)$, while band III corresponds to the MLCT transition $a_{1}{ }^{\prime}\left(p_{2}+\lambda_{s}\right) \rightarrow e\left(\pi^{*}\right)$. The more powerful $\sigma$-donor ligand octaethylporphyrin arises the $a_{1}{ }^{\prime}$ HOMO to higher energies. As a consequence, band III is redshifted and considerably gains intensity due to a stronger mixing between charge-transfer and intraligand transitions, resulting in a more pronounced hyper character for the [(OEP)Sb]Cl absorption spectrum. The intensity ratios of the absorption bands given in Table 1 therefore can reveal the relative energies of the metal valence or bitals, which control the reducing strength of the coordinated antimony(III). Further, from the energetic splittings of the band maxima, a decreasing $5 \mathrm{p}_{\mathrm{z}}$ contribution to the metalcentered HOMO can be concluded for the ligand series T( $p$ $\left.\mathrm{OCH}_{3}\right) \mathrm{PP}$, TPP, and OEP. Thus, for the tetraarylporphyrin derivatives, a smaller out-of-plane displacement of the central metal in the ground state and a lower energy for the metalcentered excited states arising from the transition $a_{1}{ }^{\prime}\left(p_{z}+\lambda_{8}\right) \rightarrow$ $a_{1}{ }^{\prime \prime}\left(s-\lambda p_{z}\right)$ can be expected. The corresponding sp bands, however, are difficult to identify in the absorption spectra, because they are obscured by the very intense intraligand bands, which cover the whole spectral region. A recent theoretical investigation ${ }^{7}$ predicts that the lowest excited states of p-type hyper porphyrins might be of the metal-centered type. Presumably this is the case for the radiationless antimony(III) complexes of $\mathrm{T}\left(\mathrm{p}-\mathrm{OCH} \mathrm{CH}_{3}\right) \mathrm{PP}$ and TPP. We suggest, that the low-temperature luminescence of $[(\mathrm{OEP}) \mathrm{Sb}] \mathrm{Cl}$ originates from a ligand-centered excited state, due to the fact that the observed emission band is very sharp, is solvent independent, and displays a Stokes shift of $3200 \mathrm{~cm}^{-1}$, which is characteristic for the lowest energy $\pi \pi^{*}$ excited triplet state of comparable metalloporphyrins. ${ }^{39,40}$

The photooxidation of chloro complexes of antimony(III) in the presence of $\mathrm{O}_{2}$, accompanied by the production of hydrogen peroxide, is a well-known photoreaction of coordination compounds of the main-group metals. ${ }^{19,41}$ It is assumed that, in the primary step of the photolysis, the lowest triplet sp excited state of the metal complex is quenched by oxygen. ${ }^{19}$ The formation of $\mathrm{H}_{2} \mathrm{O}_{2}$ during the photooxidation of antimony(III) porphyrins suggests that the light sensitivity of these compounds is also induced by a sp excited state. Indeed, the quantum yield profile found for the photolysis of [(OEP)Sb]Cl (Figure 3) resembles quite well the basic pattern of the absorption spectra ${ }^{38}$ displayed by simple main-group-metal complexes, whose lowest excited states are of the metal-centered sp type. The observed solventdependent maxima for the photooxidation quantum yield might then correspond to the band maxima of the singlet and triplet sp excited states arising from the transition $a_{1}^{\prime}\left(p_{2}+\lambda_{s}\right) \rightarrow a_{1}^{\prime \prime}(s-$ $\left.\lambda p_{z}\right)$. In analogy to many other low-valent main-group-metal complexes, ${ }^{38}$ it can be assumed that the Jahn-Teller-distorted ground-state conformation of the antimony(III) porphyrins is no longer favored in the sp excited state and that therefore a rearrangement toward a highly symmetrical in-plane geometry occurs. Calculations show ${ }^{7}$ that the lowest energy state for such a planar conformation of the metalloporphyrin corresponds to a triplet diradical species with predominantly $s^{1} \mathrm{p}_{z}{ }^{1}$ valence electron configuration.

A schematic representation of the potential energy surfaces of metal-centered (MC) and intraligand type (IL) excited states is given in Figure 4. While the MC state suffers very large structural changes during its thermal equilibration, only a minor movement of the central metal can be expected for the IL states, due to some

(39) Harriman, A. J. Chem. Soc., Faraday Trans. 1 1980, 76, 1978-1985.

(40) The phosphorescence of [(OEP)Sbv(OH) $)_{2}$ Cl shows a Stokes shift of $3200 \mathrm{~cm}^{-1}$ : Connell, C. R. In ref $12, \mathrm{p} 95$.

(41) (a) Brüll, W.; Schlägel, H. Z. Anorg. Allg. Chem. 1934, 217, 401-416. (b) Kirkbright, G. F.; Mayne, P. J.; West, T. S. J. Chem. Soc., Dalton Trans. 1972, 1918-1920. (c) Vogler, A.; Paukner, A. Inorg. Chim. Acta 1989, 163, 207-211. 
admixed charge-transfer character. As a consequence, the ligandcentered excited states have a certain probability to cross over to the photoreactive sp excited state. The efficiency of internal conversion between the lowest excited triplet states will determine the long-wavelength limit of the photooxidation quantum yield. As indicated by the energy difference $\Delta E$ (Figure 4 ), a static spectral sensitization of main-group-metal photoredox reactions ${ }^{19}$ is achieved by the presence of the chromophoric porphyrin ligand.

It is suggested that the photolysis of the antimony(III) porphyrins is initiated by an oxidative quenching of the lowest triplet sp excited state. Presumably, the radical character of the photoreactive species strongly favors dioxygen as the electron acceptor, due to the possibility of rapid spin pairing and formation of an intermediate $\mathrm{O}_{2}$ adduct, ${ }^{42}$ followed by photoinduced electron transfer. In terms of redox potentials, the limiting step ${ }^{43}$ for the activation of oxygen is the transfer of the first electron to the $\mathrm{O}_{2}$ molecule. As both oxygen ${ }^{42}$ and main-group metals ${ }^{19}$ have a pronounced tendency to participate in two-electron redox reactions, the photolysis can lead to an overall double-electron-transfer process. ${ }^{44}$ We suppose that a fast second electron-transfer step takes place between the photochemical primary products and that side reactions involving free oxygen radicals or antimony(IV) intermediates only play a minor role. The observed high recovery of hydrogen peroxide seems to confirm this assumption. Following the electron-transfer steps, the formed coordinatively unsaturated antimony(V) species is thought to be stabilized by axial ligation with hydroxide or halide ${ }^{45}$ ions present in the solution.

Since $\mathrm{H}_{2} \mathrm{O}_{2}$ is a much better electron acceptor than $\mathrm{O}_{2},{ }^{42,43}$ the oxidative quenching of the lowest $\mathrm{sp}$ excited state of the metalloporphyrin may also be achieved by hydrogen peroxide, which has been produced during the photoreduction of dioxygen. Under these conditions, the photolysis of antimony(III) porphyrins results in an overall four-electron reduction of $\mathrm{O}_{2}$ :

$$
2 \mathrm{Sb}^{3+}+\mathrm{O}_{2}+2 \mathrm{H}^{+} \stackrel{h \nu}{\rightarrow} 2 \mathrm{Sb}^{5+}+2 \mathrm{OH}^{-}
$$

The mechanisms by which metalloporphyrins react with hydroperoxides are a topic of current research. ${ }^{46}$ One possible pathway includes a two-electron oxidation of the central metal, accompanied by a heterolytic cleavage of the hydroperoxide bond. A reactive electron-deficient intermediate is formed, which is able

(42) Drago, R. S. Coord. Chem. Rev. 1992, 117, 185-213.

(43) Sawyer, D. T. In Oxygen Complexes and Oxygen Activation by Transition Metals; Martell, A. E., Sawyer, D. T., Eds.; Plenum Press: New York, 1988; pp 131-148.

(44) For a general discussion of the possible mechanisms, see: Cannon, $\mathbf{R}$. D. Electron Transfer Reactions; Butterworths: London, 1980; pp 84 91.

(45) In aqueous solvent systems, the halide-substituted antimony(V) derivatives are hydrolyzed, forming dihydroxoantimony $(V)$ porphyrins as the final products.

(46) (a) Bruice, T. C. Acc. Chem. Res. 1991, 24, 243-249 and references therein. (b) Traylor, T. G.; Tsuchiya, S.; Byun, Y.-S.; Kim, C. J. Am Chem. Soc. 1993, 115, 2775-2781. (c) Yamaguchi, K.; Watanabe, Y.; Morishima, I. J. Am. Chem. Soc. 1993, 115, 4058-4065 and references therein. to catalyze the oxidation of organic substrates. For chromium, manganese, and iron porphyrins, close relationships to the biochemical transformations mediated by cytochrome P-450 or peroxidases exist. ${ }^{46,47}$ In this connection, it is interesting to note that, upon irradiation of antimony(V) porphyrin solutions, an epoxidation of alkenes has been observed. ${ }^{48}$ We suggest that a photochemical interconversion between dihydroxoantimony(V) and antimony(III) porphyrins might be possible, passing through a reactive intermediate, ${ }^{49}$ which acts as the epoxidizing species.

The disproportionation process, occurring when the photolysis of antimony(III) porphyrins is carried out in the absence of oxygen, is assumed to involve a bimolecular oxidative quenching of the lowest triplet sp excited state of the metalloporphyrin by a second ground-state antimony(III) molecule, which suffers subsequent demetalation. An alternative mechanism initiated by an internal electron transfer from the porphyrin ligand to the sp excited central metal, followed by demetalation of the complex, might also be discussed. In any case, a complicated sequence of secondary reactions has to be considered in order to explain the overall formation of metallic antimony and antimony $(V)$ porphyrin as the final products. A detailed study of these reactions, however, was not within the scope of this work.

\section{Conclusion}

The reactivity of antimony(III) hyper porphyrins can be attributed to a reducing metal-centered sp excited state. Their photochemical and photophysical properties are consistent with the general concept developed for simple coordination compounds of the main-group metals. 19,38 Photoinduced multielectrontransfer processes are observed, which lead to the production of permanent redox products in high yields. It has been shown that a sensitization of typical main-group-metal photoreactions ${ }^{19}$ over a broad range of the visible spectral region is possible. The application of antimony porphyrins as photocatalysts for the selective activation of small molecules or the chemical conversion and storage of solar energy seems promising.

Acknowledgment. Financial support of this research by the BMFT (Grant 0329075A) is gratefully acknowledged.

(47) Ostovic, D.; Bruice, T. C. Acc. Chem. Res. 1992, 25, 314-320 and references therein.

(48) (a) Inoue, H.; Sumitani, M.; Sekita, A.; Hida, M. J. Chem. Soc., Chem. Commun. 1987, 22, 1681-1682. (b) Inoue, H.; Hida, M. Mem. Fac. Technol., Tokyo Metropolitan Univ. 1988, 38, 3883-3884. (c) Shelnutt, J. A.; Trudell, D. E. Prepr. Pap.-Am. Chem. Soc., Div. Fuel Chem. 1989, 34, 1402-1407. (d) Shelnutt, J. A.; Trudell, D. E. ACS Symp. Ser 1990, 437, 265-271. (e) Inoue, H.; Okamoto, T.; Komiyama, M. Hida, M. J. Photochem. Photobiol, $A$ 1992, 65, 221-227.

(49) We assume, that a ligand to metal charge-transfer excited state of the dihydroxoantimony $(\mathrm{V})$ porphyrin, which can be described as a porphyrin cation radical antimony(IV) species containing electrophilic oxygen ligands, might be the epoxidizing agent. Oxygen activation by cytochrome P-450 is supposed to involve a hypervalent oxoferryl porphyrin cation radical intermediates,47 with a quite similar electronic structure. Further, the reduced heme group of this enzyme is known to be closely related to the antimony(III) hyper porphyrins.11,24 